\title{
El compliance: repercusiones en la concepción de la empresa
}

Cómo citar este artículo / To reference this article / Comment citer cet article / Para citar este artigo:

Sanclemente-Arciniegas, J. (2021). El compliance: repercusiones en la concepción de la empresa. Revista Escuela de Administración de Negocios, (90), 193-212. DOI: https://doi.org/10.21158/01208160.n90.2021.2975

\section{Resumen}

El presente texto plantea un estudio sobre la noción jurídica del compliance y cómo esta repercute en la forma en la que se conciben las grandes empresas. El estudio se estructura en torno a los principales desarrollos de la figura a nivel internacional, por lo cual se evidencia que esa institución legal implica, de una parte, cambios en la identidad misma de las compañías, transformación que se expresa en nuevas interpretaciones sobre la naturaleza de las sociedades, sus obligaciones y su responsabilidad. De otra parte, ligado a lo anterior, el compliance impone mutaciones a los modelos de gobierno corporativo, en los que se trata de organizar la empresa de una manera que le permita atender los nuevos desafíos que el respeto de la ley establece, para lo que resulta necesario adoptar diferentes instrumentos que favorezcan el control de los riesgos jurídicos que se derivan de su propio comportamiento. A partir de una metodología analítica y comparativa de la doctrina y las normas internacionales, el estudio concluye que es pertinente la adopción de la institución en el caso colombiano, dado que se han presentado casos de empresas emblemáticas involucradas en grandes escándalos. La experiencia internacional enseña que el sometimiento de las grandes compañías al derecho es una condición necesaria para considerar esas organizaciones como algo positivo para la sociedad.

Palabras clave: compliance; modelo de gobierno corporativo; riesgo jurídico; naturaleza jurídica de las organizaciones; regulación jurídica empresarial.

\footnotetext{
1 Doctor en Derecho - Universidad París-Dauphine, PSL Research University. Magíster en Derecho de los Negocios y de la Economía - Universidad Paris I Pantheón Sorbonne. Especialista en Derecho Comercial -Universidad Paris II Panthéon Assas. Especialista en Derecho Público - Universidad Externado. Especialista en Derecho Privado Económico - Universidad Nacional de Colombia. Abogado - Universidad Nacional de Colombia. ORCID: https://orcid.org/0000-0002-6251-8177
} 


\title{
Compliance: \\ implications in the conception of the company
}

\begin{abstract}
This text presents a study on the legal notion of compliance and how it affects the way in which large companies are conceived. The study is structured around the main developments of the figure at the international level, reason for showing that this legal institution implies, on the one hand, changes in the very identity of the companies, a transformation that is expressed in new interpretations of the nature of the companies, their obligations, and their liability. On the other hand, linked to the above, compliance imposes mutations to the corporate governance models where the company is organized in a way that allows to meet the new challenges established by the respect for the law, for which it is necessary to adopt different instruments that favor the control of the legal risks arising from its own behavior. Based on an analytical and comparative methodology of the doctrine and international standards, the study concludes that it is appropriate to adopt the institution in the Colombian case, given that there have been cases of emblematic companies involved in major scandals. The international experience teaches that the submission of large companies to the law is a necessary condition to consider these organizations as something positive for society.
\end{abstract}

Keywords: compliance; corporate governance model; legal risk; legal nature of organizations; corporate legal regulation.

\section{Compliance: repercussões na concepção da empresa}

\section{Resumo}

Este texto apresenta um estudo sobre a noção jurídica de compliance e como ela afeta a forma como as grandes empresas são concebidas. $\mathrm{O}$ estudo estrutura-se em torno dos principais desenvolvimentos da figura internacional, dos quais se evidencia que esta instituição jurídica implica, por um lado, mudanças na identidade das empresas, transformação que se expressa em novas interpretações sobre a natureza das sociedades, suas obrigações e responsabilidades. Por outro lado, relacionado ao exposto anteriormente, o compliance impõe mutações aos modelos de governo corporativo, nos quais se trata de organizar a empresa de forma que lhe permita enfrentar os novos desafios que o respeito à lei estabelece, para os quais se faz necessário adotar diversos instrumentos que favoreçam o controle dos riscos jurídicos decorrentes do seu próprio comportamento. Com base em uma metodologia analítica e comparativa de doutrina e de normativas internacionais, o estudo conclui que a adoção da instituição é pertinente no caso colombiano, visto que já houve casos de empresas emblemáticas envolvidas em grandes escândalos. A experiência internacional ensina que a submissão das grandes empresas à lei é uma condição necessária para considerar essas organizações como algo positivo para a sociedade.

Palavras-chave: compliance; modelo de governo corporativo; risco legal, natureza jurídica das organizações; regulamentação jurídica empresarial. 


\section{Conformité:} répercussions sur la conception de l'entreprise

\section{Résumé}

Ce texte présente une étude sur la notion juridique de conformité et son impact sur la conception des grandes entreprises. L'étude est structurée autour des principales modélisations internationales du concept pour lesquelles cette conception juridique implique, d'une part, des changements d'identité des entreprises avec une transformation vers de nouvelles interprétations de la nature des entreprises, leurs obligations et responsabilités. D'autre part, la conformité impose des mutations aux modèles de gouvernance d'entreprise et leur organisation pour leur permettre de relever ces nouveaux défis légaux pour lesquels l'adoption de différents instruments favorisant le contrôle des risques juridiques qui découlent de leur propre comportement devient nécessaire. Sur la base d'une méthodologie analytique et comparative de la doctrine et des normes internationales, cette étude conclut que l'adoption de la conformité est pertinente pour les entreprises colombiennes dans la mesure où il $\mathrm{y}$ a déjà eu des cas d'entreprises emblématiques impliquées dans des scandales majeurs. L'expérience internationale montre que la mise en conformité des grandes entreprises à la loi est une condition nécessaire pour que ces organisations participent d'un modèle sociétal positif.

Mots-clés: conformité; modèle de gouvernance d'entreprise; risque juridique; nature juridique des organisations; réglementation juridique des affaires. 


\section{Introducción}

$\mathrm{E}_{\mathrm{n}}^{1}$ presente texto plantea una reflexión sobre la noción jurídica del compliance y la manera en la que repercute en la forma en la que se conciben las grandes empresas. La reflexión se estructura en torno a los principales desarrollos de la figura a nivel internacional. Así, veremos que esa institución legal implica, por una parte, cambios en la identidad misma de las compañías. Esa transformación se expresa en nuevas interpretaciones sobre la naturaleza de las sociedades, sus obligaciones y su responsabilidad. Por otra, ligado a lo anterior, el compliance impone mutaciones a los modelos de gobierno corporativo. Se trata de organizar la empresa de una manera que le permita atender los nuevos desafíos que el respeto de la ley le establece. Para esto, es necesario adoptar diferentes instrumentos que le permitan llevar a cabo la actividad de controlar los riesgos jurídicos que se derivan de su propio comportamiento.

El compliance es una institución jurídica polisémica y compleja, de origen estadounidense. Su definición se estructura en torno al problema del cumplimiento de la ley. Sin embargo, como lo afirma la profesora Frison-Roche (2016), reducir la noción al cumplimiento la privaría de todo su interés. Respetar la ley es una obligación tradicional de todos los sujetos jurídicos, no hay novedad en ese aspecto, de allí que esa asimilación tornaría la figura anodina. Lo nuevo en el compliance es plantearse eso como un problema.

Esa es una manera pertinente de abordar el asunto, ya que encara dos desafíos que enfrenta el derecho en la actualidad. Por una parte, la institución tiende a cuestionar la percepción según la cual las grandes corporaciones pueden sustraerse a la obediencia de la ley (Reich, 2020). Además, permite confrontar lógicas empresariales que plantean cómo la transgresión de la legalidad sería el modo normal de desarrollar la actividad económica, una estrategia inevitable e incluso loable (Anand, Ashforth y Joshi, 2004).
Por otra parte, ese enfoque parte de concebir el cumplimiento de la ley como un propósito que las empresas no alcanzan si no hacen esfuerzos para ello. Es necesario que se desarrollen instrumentos especiales con miras a lograrlo. En tal sentido, Gunter Teubner (2011) sostiene que el compliance se ha desarrollado como consecuencia de los graves escándalos en los que se han visto involucradas corporaciones transnacionales. Esa sería una respuesta a las críticas que se expresaron a nivel global ante la participación de grandes firmas en fraudes, corrupción o violación de derechos humanos. Los códigos de conducta aparecen como un producto paradigmático de la nueva disciplina.

$\mathrm{Su}$ adopción responde, en criterio de Teubner (2011), a presiones de los Estados, de los movimientos de la sociedad civil internacional y a las iniciativas de las empresas. Debido a esto, los efectos de la potestad normativa privada estarían generando el desplazamiento del sistema político, que deja de ser considerado la principal fuente del derecho. En ese mismo sentido, algunos autores como Arias (2020) hablan de autorreferenciación del sector privado al público.

El desarrollo de las grandes empresas ha cumplido el pronóstico de Berle y Means (1932), en el sentido de que hoy tienden a ser las principales organizaciones de la sociedad, de manera que superan en algunos casos a los Estados. De allí que su gobierno ha dejado de ser concebido como un instrumento al servicio exclusivo de sus accionistas. Las terceras partes interesadas clientes, acreedores, comunidades o autoridadesreclaman que sus intereses también se tengan en cuenta. El conflicto entre shareholderistas y stakeholderistas dejó como resultado una nueva visión de la empresa. En esta se conjuga una síntesis de posiciones que antes se consideraban antagónicas. La combinación de ambos modelos se revela como una solución que debe satisfacer 
las necesidades de las terceras partes interesadas, mientras que a largo plazo se maximiza la riqueza para los accionistas (Nwanji y Howell, 2007).

Con ese propósito, liberar las empresas de la presión de generar dividendos a corto plazo es un asunto clave en torno al cual habría un amplio consenso (Dieux, 2013). Por esta razón, integrar los intereses de los stakeholders dentro de los propósitos del gobierno de la empresa aparece como un asunto común en reflexiones de actores públicos y privados. Así lo recomiendan en los Principios de gobierno de la empresa de la Organización para la Cooperación y el Desarrollo Económicos (OCDE, 2004); la iniciativa Global Compact y los Principios Rectores de las Naciones Unidas sobre empresas y derechos humanos (Whitehouse, 2003) y las guías de las principales agremiaciones empresariales estadounidenses (Business Roundtable, 2019).

El compliance implica una transformación importante del modelo de gobierno de la empresa. En tal sentido, Griffith (2015) sostiene que en ese aspecto asistimos a una revolución silenciosa, al inicio de una nueva era. En su opinión, el compliance es determinante en el ejercicio de dos funciones básicas de la administración: el control y la supervisión de los asuntos corporativos internos. Esas son misiones tradicionales de la gerencia, de manera que la novedad allí no es el hecho de que la empresa deba cumplir la ley; lo inédito es considerar que para esto es necesario repensar la forma en la que la entidad se organiza.

Esas preocupaciones han dado origen a una nueva corriente teórica denominada la «nueva gobernanza». Sus exponentes afirman que los retos que se derivan del respeto de la ley conducen a cambios positivos en la cultura, las instituciones y el comportamiento a largo plazo de la empresa (Ford, 2005). Otros autores remarcan, con razón, que las transformaciones asociadas al compliance corresponden a un enfoque punitivo. Este se traduce en exigencias de una mayor transparencia y monitoreo de la acción empresarial, una actitud alimentada por la desconfianza que suscitan los escándalos corporativos (Baer, 2009).
La concepción de la empresa como un ente que no persigue solo dividendos privados desemboca en cuestionamientos sobre la naturaleza de esa institución y, en especial, de su organización. La integridad, la honestidad y el comportamiento ético de la empresa dejan de ser concebidos como asuntos de interés privado. Ahora pasan a ser percibidos como materias de interés público. Esto debido a que cuando se presentan fallas en esos aspectos, las consecuencias negativas deben ser soportadas por la sociedad entera. De allí que la mala organización de la empresa se identifica como la causa de la vulneración de bienes protegidos por el derecho, lo que puede dar origen a una responsabilidad de tipo criminal (Missas-Gómez, 2018).

La sanción penal de la persona jurídica es un rasgo distintivo del compliance. Su pertinencia ha generado acalorados debates en la doctrina del derecho continental. Sin embargo, ese tipo de responsabilidad no es una nueva institución jurídica, pues corresponde a una estrategia adaptada en los Estados Unidos hace más de cien años (Hasnas, 2009). El argumento de que los daños que generan las empresas tienen efectos muy superiores a los que causan los individuos es el principal argumento que se ha esgrimido en respaldo de la responsabilidad penal (Friedman, 2000).

Ahora bien, para desarrollar los asuntos planteados dividimos el artículo en dos partes. En la primera de ellas analizamos las transformaciones en la interpretación del objeto de las empresas, sus nuevas obligaciones y la evolución que se plantea en materia de responsabilidad. En la segunda parte nos referimos a las innovaciones en el gobierno de la empresa que tienen origen en el compliance. Allí haremos referencia a los cambios en la estructura administrativa y a los nuevos instrumentos a los que la empresa debe acudir, con miras a garantizar el cumplimiento de la ley. 


\section{Las transformaciones en la concepción de las empresas}

$\mathrm{E}^{\mathrm{l}}$ compliance trae consigo una transformación en la concepción misma de la empresa. Se trata de uno de los últimos estadios dentro de un proceso que inició desde la primera mitad del siglo XX con la toma de conciencia sobre los impactos extraeconómicos de las grandes corporaciones. Desde esa época, autores como Georges Ripert (1946), Peter Druker (1946) y Wolfgang-Friedmann (1957) alertaron sobre la mutación profunda que la empresa podía generar en las sociedades democráticas. Conviene resaltar que ese es un análisis propio de pensadores que valoraron como superior el modelo económico capitalista. Sin embargo, evocaron los riesgos que podrían derivarse para ese modelo de un desarrollo descontrolado del poder económico privado. Un rasgo esencial de sus reflexiones fue considerar las empresas como entes que desbordan el ámbito natural de los asuntos privados.

La reflexión sobre las corporaciones modernas y la propiedad privada planteada por Adolf Berle y Gardiner Means (1932) constituye, a nuestro juicio, la fuente de una mutación radical en la interpretación del poder empresarial, así como sobre su forma de gobierno. La observación que ellos realizaron sobre la separación entre la propiedad, ejercida por pequeños accionistas, $y$ el control de las grandes corporaciones estadounidenses, ejercida por los administradores, demostró los intereses divergentes de esos dos actores.

The modern corporation and private property (1932) es una de las obras más citadas en las últimas décadas. Dalia Tsuk (2005) recuerda la reseña que hizo de ese texto el juez Jerome Frank, quien sostuvo que ese libro podía clasificarse, junto con la Riqueza de las naciones, de Adam Smith, como una descripción pertinente de la existencia de una nueva época económica. Nodoushani y
Nodoushani (1999) se refieren a la obra como un cambio mayor en el paradigma acerca del gobierno de las empresas. Wells (2009) observa que, pese a que las ideas planteadas en el libro habían circulado antes, esa obra es considerada el referente fundador de la corporate governance.

Sin embargo, Berle y Means también formularon otra tesis que ha tenido menos difusión, pero que evoca cambios aún más radicales. Sostuvieron que el surgimiento de la corporación capitalista condujo a tal concentración del poder económico que permite a esos entes privados competir en igualdad de condiciones con el Estado moderno. Observaron que las pretensiones estatales de regular a la corporación debían hacer frente a compañías cada vez más poderosas que hacían todo lo posible por evitar esa regulación. En consecuencia, pronosticaron que esos actores económicos de naturaleza privada suplantarían al Estado como la principal forma de organización social.

En ese sentido, afirmaron que los estatutos de las sociedades podían llegar a considerarse como las normas constitucionales de un nuevo tipo de Estado. En un escenario en el que las corporaciones asumen roles propios de entidades estatales, casi cien años después de dichas consideraciones, el poder de las grandes corporaciones no ha cesado de aumentar. De allí que autores como Gunter Teubner (2011) califiquen los códigos de conducta de las empresas transnacionales como constituciones, en el sentido estricto del término. Por el contrario, en lo que concierne al Estado hemos asistido a un repliegue importante de su presencia tanto en la actividad económica como en otros ámbitos de la vida social. Sus limitaciones son más agudas cuando se considera la esfera internacional, el ámbito natural de las grandes empresas. 


\subsection{Hacia una concepción de la empresa como un ente político}

La transformación que implica el compliance añade una dimensión política a los rasgos típicos de ente privado que caracterizan a la empresa. Esta característica agrega complejidad a una institución cuya particularidad siempre le ha planteado retos al derecho. El análisis de Millon (1990) da cuenta de la evolución de la discusión en torno a la concepción de la empresa. Este autor sostiene que, aunque se trata de un debate que sigue abierto, la discusión se estructura en torno a los intereses - privados o públicos - que deben ser privilegiados. Quienes entienden la empresa como un ente que debe servir el interés general se fundan en el carácter artificial de las personas jurídicas. Estas son puras ficciones cuya capacidad de acción se la deben a los atributos que les reconoce el derecho. De allí que no es razonable que pretendan desconocer los valores que inspira el sistema jurídico que les sirve de sustento.

Sin embargo, la tesis que ha predominado desde la década de los setenta del siglo pasado es la del egoísmo corporativo planteado por Milton Friedman (1970). En esta perspectiva, la empresa se concibe como un ente al servicio exclusivo de sus inversionistas. De allí que la única responsabilidad que se les puede imponer es la de generar dividendos.

Las dificultades del derecho para proyectar una mirada completa de la empresa se explican por el carácter multisistémico de esa institución. En esa perspectiva, el compliance expresa un nuevo intento del discurso jurídico con el objetivo de asir un fenómeno que le ha sido esquivo. En efecto, la empresa es una institución cuya naturaleza no se puede reducir solo a su dimensión jurídica. Además, aun dentro de este campo, exhibe características que interesan a distintos subsistemas, como, por ejemplo, el derecho laboral, comercial o tributario. Por otra parte, la concepción de la empresa dentro del sistema económico o en las ciencias de la administración genera planteamientos que impactan el derecho y la política.
En tal sentido, es pertinente destacar el concepto de corporación formulado por Peter Druker (1946) desde la perspectiva de la administración de empresas. En esa concepción el impacto y la importancia de las grandes corporaciones desborda el ámbito reducido del mundo económico y empresarial. La gran empresa se concibe como un actor esencial que anuncia un nuevo tipo de sociedad. De allí que, de acuerdo con Druker, la dirección de las corporaciones debe integrar altos estándares éticos, ya que la empresa debe ser portadora de valores y principios que benefician a la comunidad. Esa interpretación converge con la tesis de Berle y Means acerca de la empresa como actor político de primer orden dentro de la sociedad industrial.

Diferentes doctrinantes han retomado la idea de la naturaleza política de las organizaciones empresariales. Así, Wolfgang Friedmann (1957) abogó por una nueva visión jurídica de las grandes empresas al tomar como fundamento los postulados de Berle y Means, así como los de Druker. En consecuencia, planteó la necesidad de cambiar el enfoque que orienta la regulación de esas entidades, de modo que se deje de verlas como organizaciones que gestionan solo intereses particulares. Lo anterior, a la luz de las actividades propias de los gobiernos que realizan las grandes corporaciones.

En un sentido similar, Jean-Philippe Robé (2014) sostiene que los pronósticos de Berle y Means son hoy una realidad. Por tanto, afirma que debemos tratar a las grandes corporaciones como instituciones de naturaleza política. De esa forma podemos situarlas como actores determinantes dentro del actual sistema de poder global. Si no se tienen en cuenta esas características, las empresas no solo serán los principales centros de poder, sino que podrán disponer de él sin las restricciones legales a las que se encuentra sometido el ejercicio de las potestades estatales. 
De esta manera los efectos políticos de la concentración del poder en torno a las grandes corporaciones han impuesto una reevaluación de la naturaleza de esa institución. De allí que las reflexiones jurídicas tradicionales sobre la empresa se revelan como incompletas, pese a concebirla como una institución compleja que articula los intereses disparares de los empresarios, los trabajadores y el Estado. Esta insuficiencia queda demostrada en la trayectoria doctrinaria de autores como Philippe de Woot (1968), quien en los años sesenta escribe su libro Pour une doctrine de l'entreprise. En ese primer estadio, el esfuerzo teórico en el marco del derecho de los negocios se centró en aprehender, desde la perspectiva jurídica, los desafíos planteados por la interacción de esos tres actores en el seno de la empresa.

Sin embargo, 45 años después, Woot (2013) publica un nuevo texto en el que llama a repensar la empresa. A su juicio, es necesario tener en cuenta las dimensiones políticas y éticas de la institución. En tal sentido, y en la misma línea de Berle y Means, plantea que las corporaciones son entidades que ejercen un poder de naturaleza política, ya que tienen la capacidad de controlar asuntos que, de ordinario, se relacionan con actividades del gobierno. Así, ellas toman o influencian decisiones determinantes en la vida de personas que en principio les serían ajenas. Esas decisiones son aún más importantes en materia de desarrollo tecnológico, por lo cual las empresas aparecen como el principal mediador entre la ciencia y la sociedad.

Esas expresiones doctrinarias justifican la afirmación de la profesora Frison-Roche (2019), según la cual el compliance es una nueva disciplina que plantearía un choque frontal frente a los principios fundantes del derecho de sociedades. En su sentir, la institución cuestiona tanto el enfoque institucionalista como la teoría contractualista de la firma, la cual se funda en la ficción jurídica de la personalidad moral. Esto puesto que, en línea con la metodología de Gerard Farjat (Sanclemente-Arciniegas, 2018), el compliance impone un análisis jurídico substancial de la realidad económica.
Lo mencionado implica, por tanto, desbordar los análisis formalistas que cultivan la perfección teórica de las instituciones, pero que son incapaces de dar cuenta de la complejidad de las relaciones que entretienen el derecho y la economía. Solo situados en esa perspectiva es posible afirmar, como lo hace Frison-Roche (2016) que el compliance es un derecho político que sitúa al ser humano como centro de las actividades empresariales y de las dinámicas del mercado. Como veremos en los acápites siguientes, de esta concepción se desprenden nuevas obligaciones y nuevas responsabilidades.

\subsection{La concepción política implica a la empresa en la protección de derechos}

La interpretación de las grandes empresas como entes políticos tiene impactos significativos en cuanto a sus obligaciones. La idea central es que, debido a ese carácter, la empresa como toda institución pública debe estar sometida a la ley y tiene como finalidad última la protección del interés general. Esto representa un giro copernicano frente a la forma en la que se ha entendido hasta ahora la figura. En tal sentido, la revista Archives de Philosophie du Droit dedicó un número temático a las nuevas relaciones entre lo público y lo privado. En la presentación de la reflexión, el profesor René Sève (1997) afirmaba que se viene presentando un cambio de signo entre lo público y lo privado en materia de derecho económico. Los atributos simbólicos asociados a lo público, como el espacio de lo universal, del bien común o de la protección del interés general, son puestos en duda.

En su lugar, el mercado se erige como el modelo a seguir (Frison-Roche, 1995), de modo que sería una herramienta más eficiente para alcanzar los mismos fines que se propone el Estado. Así, la noción de compliance, al postular la empresa como un ente público a cargo de la protección del ser humano, marca un giro importante en la reflexión jurídico-económica. Por esta razón, Reyna (2017) sostiene que la institución implica una ruptura frente a visiones tradicionales del derecho. 
En una perspectiva similar, Gaudemet afirma que «evoca el advenimiento de un nuevo mundo» (2016, p. 5), y Frison-Roche (2018, p. 23) la identifica como un «hito a partir del cual los asuntos del cumplimiento normativo serán vistos desde una nueva perspectiva». Cordier-Palasse (2016, p. 129) afirma que «el compliance trae consigo una nueva cultura dentro la cual se debe reinterpretar el papel de la empresa». Aunque las razones con fundamento en las cuales se afirma la ruptura difieren, se identifica como criterio común la idea que también plantea Adela Cortina (2003), según la cual las buenas empresas son un bien público. De esta manera, no son entes que sirven solo a bienes privados.

Así, el hecho de que la empresa, reemplazando al Estado, conquiste y comercialice ámbitos cada vez más amplios de la vida social permite exigirle que cumpla con las cargas que deben soportar los entes públicos. En tal sentido, en su obra Gerard Farjat (2004) postula la pertinencia de una nueva expresión: la economía del derecho. Esta se estructura a partir de la noción de Estado de derecho, que tuvo como objetivo someter el ejercicio del poder estatal a un control jurídico. Lo anterior con el fin de proteger los derechos fundamentales de las personas. La noción de economía de derecho tiene los mismos propósitos, sin embargo, el sujeto de control no es el poder político, sino el poder económico.

Así, dado que las grandes empresas han acumulado poderes similares $y$, en ocasiones, superiores a los del Estado, resulta necesario que el derecho profundice el control jurídico sobre su comportamiento. De lo contrario, al igual que el Estado, la empresa podría sucumbir a la tentación totalitaria. La noción de economía del derecho se revela como pertinente a la luz de la invasión por la lógica mercantil de ámbitos que, en perspectiva tradicional, eran considerados como ajenos a las dinámicas del mercado.

Someter las grandes empresas al derecho parecería un asunto sencillo que no representa mayores dificultades. Así, el compliance, en cuanto institución que se articula en torno al cumplimiento de la ley, carecería de interés. No obstante, la dinámica económica internacional demuestra que ese propósito se revela como un desafío. En tal sentido, Jean-Philippe Robé (2014) observa que, en el contexto propio de la globalización, esas organizaciones se han visto beneficiadas por una redistribución profunda del poder. En ese escenario, los Estados nacionales han perdido poder, al tiempo que las empresas multinacionales emergen como actores cuya regulación se presenta como imposible. Lo anterior, dada la ausencia de un Estado internacional con capacidad de ejercer una coerción efectiva a ese nivel.

Como consecuencia, las corporaciones pueden evadir sin gran esfuerzo el cumplimiento de leyes estatales que no les agradan. El uso sofisticado de las herramientas que el mismo derecho les ofrece permite a las compañías evitar los efectos de esta razón, autores como Godechot-Patris (2015) han hecho referencia a un modelo de law shoping. Dentro de él, el derecho mismo se interpreta como una mercancía. Los Estados se ven forzados a entrar en una competencia y ofrecer como un producto la inexistencia o reducción de normas que imponen obligaciones, impuestos u otras condiciones. Esto, con miras a atraer el capital del que disponen las grandes corporaciones.

$\mathrm{Al}$ contario de la irresponsabilidad a la que aspiran ciertas empresas, el derecho del compliance las obliga a proteger el interés general. En tal sentido, la profesora Frison-Roche (2016) hace referencia a la imposición de una nueva obligación: la de proteger fines monumentales. Esto indica que a las empresas les corresponde, dado el papel que juegan en diferentes sectores, asumir la protección de valores que, en perspectiva jurídica, son importantes.

Tales bienes son variados y dependen de la naturaleza y el objeto social de las empresas. Allí se incluyen aspectos tales como la protección del medio ambiente, los datos personales, la lucha contra la corrupción y la protección de los derechos humanos, entre otros. Conviene señalar que no 
se trata de imponer a una organización privada obligaciones propias de un ente público. Se trata de empresas que han devenido a los principales actores sociales y han asumido así roles comparables con los del Estado.

Por tal razón, corresponde a ellas y no al Estado atender la protección del interés general en esos frentes. De allí que la noción del Estado garante de derechos se ha extendido ahora a la empresa. La concepción de la empresa como garante de derechos (Dópico, 2013; Meini-Méndez, 1998; Gómez-Navarro y Fernández-Riquelme, 2019) se explica en referencia a la situación particular en la que ella se encuentra frente a determinados bienes jurídicos. En esos eventos, la empresa asume la posición de garante dado que el ejercicio de su actividad económica la sitúa en la posibilidad de vulnerar valores importantes para el derecho.

\subsection{La mutación de la responsabilidad de la empresa}

La idea según la cual la empresa es un ente político que debe proteger el interés general desembocó en transformaciones de su responsabilidad. Esa evolución que, a nuestro juicio, inicia con las reflexiones de Berle y Means (1932), fue pronosticada como algo negativo por uno de los fundadores de la corriente de Law and Economics. En efecto, la reflexión de Henry G. Manne (1962) reconoció la pertinencia de las ideas según las cuales la separación tradicional entre el sector público y el sector privado devenía borrosa.

El Estado asumía algunas actitudes propias del sector privado, al tiempo que las empresas asumían las apariencias, las actitudes y las funciones propias del gobierno. Sin embargo, Manne se opuso a la responsabilidad social empresarial con ideas similares a las que expondría en los años setenta Milton Friedman. En su opinión, la responsabilidad social empresarial no era una buena motivación para el comportamiento de las corporaciones; puesto que, aun cuando la firma realizara algunas acciones altruistas, en últimas, de esas acciones se derivaban beneficios económicos. También expresó su preo- cupación por la amplia aceptación que esas ideas tenían entre los directivos de las compañías. Sostuvo que la aquiescencia de los líderes corporativos ante las teorías de la responsabilidad social empresarial podría, en última instancia, dar lugar a que tales muestras de altruismo acabaran por establecerse como obligaciones legales.

El compliance puede entenderse como el cumplimiento de la predicción de Manne. Los postulados de la responsabilidad social empresarial acabaron por ser compartidos por la gran mayoría de los empresarios. De allí que sus recomendaciones tienden a convertirse en obligaciones positivadas en la ley (Tricot, 2016). La misma tendencia se constata en lo que hace referencia a los organismos internacionales. Tanto los principios de gobierno de la empresa de la OCDE (2004) como la iniciativa Global Compact y los Principios Rectores de las Naciones Unidas sobre empresas y derechos humanos sirven de base para impulsar una transformación legal en la responsabilidad de la empresa. Sin embargo, el compliance se aparta de la concepción tradicional de la responsabilidad social empresarial, pues apela a la coerción jurídica para imponer los compromisos que antes eran voluntarios.

La idea es forzar a las grandes corporaciones a que se sumen a la protección de valores que la voluntad general considera importantes (Whitehouse, 2003, p. 299). De manera que la nueva noción no se conforma con las proclamaciones públicas de las empresas dirigidas a reconocer sus compromisos con la sociedad. El compliance acoge los buenos propósitos empresariales con suspicacia (Gonzalo, San-José y Ruiz-Roqueñi, 2017). Por tanto, sus herramientas responden a una exigencia de seriedad que va más allá de las operaciones de marketing y exige compromisos administrativos y financieros adecuados.

Así las cosas, la primera de las obligaciones que la empresa debe asumir en ese nuevo contexto es la de vigilarse a sí misma. El incumplimiento de la ley deja entonces de ser concebido como una 
estrategia que se puede implementar con miras a obtener éxito en el mercado. En lugar de esto, la no conformidad con las normas pasa a ser considerada un defecto grave que interpela la forma en la que la entidad se organiza (Sanclemente-Arciniegas, 2019). El compliance se estructura a partir de esa problemática, a fin de atenderla con estrategias ex ante y ex post (Gaudemet, 2016). A nivel ex ante, se trata de que la empresa desarrolle una actitud proactiva que le permita identificar y prevenir los riesgos de incumplimiento que se desprenden del cumplimiento de su objeto. A nivel ex post, la empresa asume la responsabilidad de ser la primera en detectar y sancionar las actividades de sus directivos o empleados que se aparten de la legalidad.

La vigilancia de su propia conducta es una responsabilidad esencial de la empresa dentro del derecho del compliance. El estatus que se le reconoce a esa actividad se explica por la magnitud de las consecuencias negativas que se desprenden de la negligencia empresarial. Así, de la misma forma en que se ha dicho que una buena empresa es un bien público, puede afirmarse que aquella negligente es un riesgo para toda la comunidad. En tal sentido, el compliance pretende convertirse en una herramienta jurídica que vincula a la empresa en la protección de los bienes jurídicos más importantes: los derechos fundamentales (Garat, 2018; Gómez-Navarro y Fernández-Riquelme, 2019; Pereira, 2018).

En este sentido, esos valores jurídicos estructurantes del Estado de derecho han dejado de ser una carga que incumbe solo al poder público. Diferentes ordenamientos jurídicos alrededor del mundo obligan a las empresas a adoptar, de manera proactiva, medidas que eviten que sus directivos, trabajadores o contratistas violen los derechos humanos. Esa tendencia se aceleró como reacción al derrumbe del Rana Plaza en Bangladesh. Ese edificio albergaba, en condiciones deplorables, varias fábricas que maquilaban textiles para empresas multinacionales y se derrumbó causando más de mil víctimas fatales.
En Francia, a raíz de ese escándalo, se adoptó la Ley 399 de 2017 denominada «ley del deber de vigilancia». Según Mavoungou (2019), mediante ella se expresa un enfoque moralizador que impuso a las grandes empresas, entre otros, los siguientes deberes: a) el deber de adoptar un plan destinado a identificar y prevenir la ocurrencia de riesgos de violaciones de derechos humanos; b) el deber de controlar riesgos ambientales; y c) el deber de prevenir y controlar riesgos para la salud de las personas.

Otra expresión mayor en la transformación de la responsabilidad empresarial es la tendencia a castigar penalmente las faltas al deber de vigilancia. Ese tipo de represión puede afectar tanto a la persona jurídica como a sus dirigentes. Parecería entonces que, ante las insuficiencias que experimenta el derecho para aprehender el fenómeno de la empresa, se haya optado por acudir a la última ratio: el castigo penal.

En tal sentido, Jean-Philippe Robé (2014) sostiene que, frente a las dificultades de las diferentes disciplinas para dar cuenta de la realidad de la empresa, el derecho debe adoptar un análisis antidisciplinario. De esta forma, propone abandonar los enfoques interdisciplinarios que, a partir del reconocimiento de la complejidad de la empresa, han desembocado en la configuración de un ente que pretende sustraerse del cumplimiento del derecho. Por esta razón observa que la ficción de la personalidad jurídica se encuentra en la base de esa institución. En consecuencia, afirma que es necesario que el derecho despliegue todas las herramientas necesarias a fin de asegurarse de que los entes que él crea respeten los valores propios del discurso jurídico, el primero de los cuales es el respeto del interés general.

La responsabilidad penal de las personas jurídicas es un rasgo propio del derecho del compliance que ha generado encendidos debates en la doctrina jurídica del derecho continental (Arroyo y Nieto, 2013; Uribe-Manríquez et al., 2017). Sin embargo, ese es un debate estéril que se centra en aspectos 
formales. De allí que Ramírez y Ferré (2019, p. 115) afirmen que se trata de discusiones inacabables que se prologan mientras los delitos empresariales no cesan. Aunque, a nivel internacional, ese no es un debate de actualidad jurídica.

Ese tipo de responsabilidad existe en la legislación estadounidense hace más de cien años (Hasnas, 2009). En Francia, la institución fue adoptada con la reforma del Código Penal de 1982. Esta ha sido concebida como un desafío que debe ser superado (Tricot, 2012) so pena de dejar sin castigo las actividades que tienen mayor impacto negativo sobre los bienes jurídicos que tutela el sistema jurídico. En efecto, según señala Friedman (2000), el daño que se deriva de la criminalidad de las personas físicas es secundario en comparación con aquel del que son responsables las personas jurídicas. De allí que el derecho penal colombiano no debería permanecer indiferente frente a esas tendencias.

\section{Las transformaciones en los modelos de gobierno corporativo}

$\mathrm{E}$ compliance implica una trasformación de los modelos de gobierno corporativo tendiente a garantizar las nuevas obligaciones y responsabilidades de la empresa. Se trata de una evolución que, a nuestro juicio, tiene sus orígenes en las reflexiones de Berle y Means (1932). En efecto, el que la empresa deba servir al interés general es un postulado central de la obra de los fundadores de la teoría de la corporate governance. Sin embargo, según Dalia Tsuk (2005), ese rasgo esencial de esa doctrina quedó eclipsado debido al impulso que tomó lo que ella denomina «el enfoque individualista $\gg$.

En tal sentido, Tsuk (2005) remarca el hecho de que las tesis de Berle y Means fueron formuladas dentro de la atmósfera intelectual que fundamentó el New Deal. Se trataba de un momento en el que las ideas keynesianas tenían una amplia aceptación entre los responsables políticos y los principales académicos. De esta manera, la pérdida de influencia de la concepción del gobierno de la empresa como un dispositivo que debía servir el bien común va de la mano con el surgimiento de las ideas críticas del keynesianismo.

En la actualidad, el compliance se estructura en torno a las doctrinas que critican el hecho de reducir la empresa a simple generadora de dividendos pe- riódicos para sus accionistas. Esa posición es cuestionada ya que la primacía que se otorga a generar dividendos en el corto plazo le impide servir de manera adecuada tanto a los accionistas como a la comunidad. En términos de Danet (2008), la miseria de la corporate gobernace consiste en reducir de manera simplista el gobierno de la empresa a una relación entre el agente y el principal.

Los problemas que se derivan de esa concepción fueron detectados de forma acertada por Berle y Means. Por tanto, plantearon que el ejercicio del derecho de propiedad por parte de los accionistas era un mecanismo inadecuado para guiar la acción de la empresa. En consecuencia, sostuvieron también que sería ineficaz permitir que fuera gobernada para satisfacer solo los intereses de sus propietarios. En la misma línea de esos planteamientos, Branston, Cowling y Sugden (2006) afirman que los modelos de gobierno corporativo deben ser concebidos como asuntos propios de la discusión política. Esa sería la forma de lograr que las empresas, así como los entes públicos, se gobiernen pensando en el interés general.

Ante ese tipo de cambios, Jackman (2015) afirma que el compliance implica transformaciones profundas en los modelos de gobierno de las empresas. Una revolución caracterizada por situar en el centro 
de las preocupaciones de la gerencia a una cultura de responsabilidad hacia valores que, en principio, se conciben como externos a la organización. En tal sentido, la doctrina internacional ha hecho referencia un nuevo modelo de gobernanza corporativa estructurado bajo la idea de una convergencia entre los postulados propios de la corporate gobernance y la responsabilidad social empresarial (Gill, 2008). Un modelo que da cuenta del rol cada vez mayor del sector privado en la configuración de los asuntos públicos, al tiempo que se reduce el poder regulador del Estado.

De esta forma, se reconoce la existencia de una pluralidad de actores que, al gozar de un poder significativo, concurren a la formación de un nuevo modo de gobernanza caracterizado por las relaciones complejas que entretejen en su seno actores portadores de lógicas diversas, públicas y privadas, nacionales e internacionales (Santos, 1987). A continuación, se refieren dos concepciones del modelo de gobierno corporativo. Una, tiende a privilegiar el enfoque punitivo tanto en el interior de la empresa como en la relación entre la empresa y el Estado. La otra privilegia un enfoque colaborativo en el que empresa y Estado se conciben como entes complementarios en la misma causa de proteger el bien común.

\subsection{Reconfiguración del gobierno corporativo en entorno al ejercicio de la facultad sancionatoria}

La doctrina internacional (Frison-Roche, 2016; Requena y Cárdenas, 2016; Teubner, 2011) coincide en señalar que el derecho del compliance se ha estructurado, en buena parte, como reacción a los graves escándalos en los que se han visto envueltas las grandes empresas. Como consecuencia de esos abusos empresariales, los ciudadanos, las autoridades y los inversionistas reforzaron sus exigencias para que las compañías controlen de manera efectiva su conducta.

Producto de esos requerimientos tanto los Estados como las empresas adoptan dispositivos jurídicos dirigidos a sancionar de manera severa la criminalidad empresarial. Esto ha conducido a una reconfiguración de los modelos de gobierno corporativo tendientes a organizar la empresa de una manera que impida que se concreten los riesgos de incumplimiento normativo. De esa forma, el ejercicio del poder de sanción es un rasgo característico del derecho del compliance que está generando cambios en la estructura administrativa de las corporaciones. El carácter coercitivo diferencia las instituciones del compliance frente a aquellas dedicadas al desarrollo de actividades propias de la simple responsabilidad social empresarial (Tricot, 2016). De manera que no se trata solo de implementar estrategias de marketing con el propósito de mejor la percepción de la empresa.

Siguiendo los planteamientos de Berle y Means acerca de la empresa como un ente político, el derecho del compliance plantea redistribuir el poder en el interior de la organización, a fin de garantizar que quienes ejercen la dirección tengan contrapoderes reales. Esto implica modificaciones en la estructura organizativa de la corporación al dar cabida a instituciones propias del compliance que deben situarse al mismo nivel de la alta dirección. En tal sentido, se ha afirmado que «la empresa y su estructura jerarquizada, organizacional y gerencial, requiere para su correcto funcionamiento de la adopción de medidas concretas que garanticen la cultura ética al máximo nivel» (Ramírez y Ferré 2019, p. 16).

De esta manera el compliance implica una reconfiguración administrativa de las empresas, pues se deben crear nuevas instancias que sean responsables de la función de compliance y cuenten con independencia frente a la gerencia. Así se impiden los conflictos de interés y que la empresa se vea abocada a cumplir, a cualquier costo, los objetivos de la alta gerencia. El compliance, entonces, trae consigo la noción de economía del derecho que planteaba Farjat (SanclementeArciniegas, 2018) y la internaliza en la empresa. La idea es someter el ejercicio del poder corporativo al derecho, condicionando por ley el desempeño de 
la sociedad, con miras a asegurar la licitud de todas sus actuaciones. En ese empeño, la empresa debe demostrar que se ha organizado de una manera tal que se excluye la posibilidad de que lleve a cabo actividades contrarias al derecho.

Esta transformación no tuvo un origen exclusivo en la dinámica propia de la competencia económica internacional. Expresa también a una voluntad política que, desde el Foreign Corrupt Practices Act Forein (Sanclemente-Arciniegas, 2020) se interesó por exigir compromisos éticos a las grandes empresas. Se trata de condicionar jurídicamente el ejercicio del poder económico que tiene efectos globales. En tal sentido, Boursier (2017) plantea que, como producto de esas preocupaciones, hemos asistido a una mundialización del derecho penal. Ese escenario se caracteriza por los efectos limitados que tiene de la soberanía estatal en el ámbito internacional propio de las grandes empresas. De allí que los Estados tienden a exigir que las empresas realicen esfuerzos serios por controlar su propio comportamiento so pena de severas sanciones. Así, el enfoque sancionatorio se ha revelado como una manera eficaz de modificar los modelos de gobierno corporativo y la cultura empresarial en general.

Esta perspectiva apela, entonces, a un reforzamiento de la naturaleza y el monto de las sanciones a imponer, así como a una diversificación de las penas aplicables y de los posibles responsables. El énfasis en la sanción se funda en las ideas planteadas por Becker (1968), quien observó que los actores económicos calculan el valor esperado de una conducta ilegal frente al costo de las consecuencias de la detección. Por tanto, a fin de disuadir de manera efectiva las infracciones ha sido necesario aumentar el rigor de las sanciones, lo cual incrementa de forma considerable los costos derivados del incumplimiento.

El enfoque sancionatorio tiene efectos ex ante y ex post sobre los modelos de gobierno corporativo. A nivel ex ante, el compliance obliga a las empresas a reorganizarse implementando estructuras administrativas propias del derecho del compliance.
El objetivo es que la empresa desarrolle una cultura de cumplimiento de la legalidad, de manera que adopte dependencias administrativas e instrumentos normativos dirigidos a evitar que se configure el riesgo de incumplimiento normativo. El hecho de que la empresa no adopte esas herramientas y se presenten casos graves de incumplimiento normativo la hace responsable de los daños causados.

Por ejemplo, en Francia, en el 2016 se adoptó la Ley 1691, conocida como Ley Sapin 2. Esa norma obliga a las empresas a dotarse de un programa de cumplimiento, de códigos de conducta y de mecanismos para la protección de los denunciantes internos de actos ilícitos. En el mismo sentido, en España, en el 2015, se adoptó la Ley Orgánica 01 mediante la cual se dispuso que las personas morales pudieran quedar exentas de responsabilidad criminal a través de los denominados compliance programs, o, como los denomina el Código Penal español, «modelos de organización y gestión» (León, 2020).

A nivel ex post, el compliance exige que las empresas ejerzan el poder del que disponen, a fin de reprimir los actos ilegales que se comentan por parte de sus directivos, empleados, proveedores, contratistas o usuarios. Esto hace necesario que la organización se dote de códigos de conducta en los que tipifique las actividades proscritas, los procedimientos para ejercer el poder represivo interno y las instancias encargadas de esa función. El poder sancionador de las empresas es un asunto que interesa al compliance dado que es una herramienta importante para lograr la protección del interés general. El ejercicio de ese poder es un ámbito en el que se presenta, una vez más, la inversión de las concepciones entre lo público y lo privado.

En tal sentido, Gunther Teubner (2011) observa que, al contrario de lo que ocurre con el Estado, que sufre de limitaciones para disciplinar la actividad económica internacional, las grandes corporaciones pueden ejercer de manera eficaz represalias sobre sujetos que se hallan bajo su ámbito de influencia. Sin embargo, no se trata de 
que las empresas disciplinen a sus relacionados con miras a proteger su propio interés. Gaillard (1985) ha sostenido que la potestad sancionadora que el derecho reconoce a las empresas puede ser entendida como un poder que se les otorga para que protejan intereses diferentes al suyo: es decir, un instrumento para la protección del interés general.

También a nivel ex post, entre los procedimientos sancionatorios que adelantan las autoridades administrativas o penales, el derecho tiende a facultarlas para que impongan, como parte de la sanción, la obligación de que la empresa se dote de instrumentos de compliance. De manera que el proceso sancionatorio deviene una instancia de escrutinio del modelo de organización y gestión de la firma. Lo anterior, bajo el entendido de que el incumplimiento grave de la legalidad implica que la empresa se encuentra mal organizada. Ese mal funcionamiento es intolerable para el derecho, pues genera la vulneración de bienes relevantes en materia jurídica.

Por esta razón, la OCDE (2011) destaca el remedio que adoptaron las autoridades europeas de la competencia en el caso de Microsoft. Ante la violación de la legalidad, esa empresa fue obligada a dotarse de un compliance officer y de un programa de cumplimiento como parte de la sanción que se le impuso. Esas instancias fueron dotadas de independencia administrativa y financiera. Así, la sanción consiste en una desaprobación del modelo de gobierno de la empresa y el remedio que se formula es un cambio de dicho esquema, con miras no solo a resarcir el daño, sino a garantizar que los actos reprensibles no se reproduzcan.

\subsection{Reconfiguración del gobierno corporativo por la internalización de la regulación estatal}

En oposición a la tendencia que pretende reformar el gobierno corporativo a partir del ejercicio de la facultad sancionatoria, se ha postulado un nuevo enfoque que privilegia la participación de la empresa en el logro de los fines sociales y políticos del Estado. La primera de las actividades estatales que deben asumir las empresas es la actividad de inspección, control y vigilancia de su propio comportamiento.

Este modelo se inscribe dentro de una corriente más amplia conocida como «nueva gobernanza» (Lobel, 2004; Karkkainen, 2004), por la cual el Estado convoca a las empresas y otros actores sociales a compartir la responsabilidad de cohesionar un cierto orden social. Se trata de un cambio fundamental en el paradigma jurídico, en la medida en que el Estado deja de ser concebido como la fuente esencial a partir de la cual se organiza la sociedad; abandonando así la perspectiva estatocéntrica, burocrática y jerarquizada. En lugar de esto, la nueva gobernanza hace referencia a un modelo más abierto, participativo, orientado al consenso, flexible, integrador y pragmático.

En esa perspectiva, el compliance implica una trasformación del gobierno de la empresa destinada a internalizar en la organización las actividades propias de las autoridades de regulación. Así, Ford (2005) observa que la estructura de la organización empresarial es objeto de un análisis detallado por parte de esas autoridades y de los jueces con quienes la empresa está en constante interacción. A partir de allí, el cumplimiento de la ley aparece como un objetivo común que persiguen tanto los actores públicos como ciertas dependencias de las organizaciones privadas. La empresa adapta su estructura organizativa en torno a dicho objetivo. Para esto se dota de instancias que, además de cumplir ese propósito, aseguran una relación armónica con las autoridades públicas y con la sociedad en general.

Esa manera de entender el gobierno de la empresa y la actividad de los entes estatales se concibe como superior al modelo de comando y control propio de la regulación tradicional. La idea es que resulta más eficaz vincular la cultura y la organización de las empresas a la protección de bienes que la comunidad considera relevantes, que pretender imponer esos valores por vía coercitiva. 
En Francia, el estudio dirigido por Borga, Marin y Roda (2018) se orienta en un sentido similar. El cumplimiento normativo se concibe como un factor que ha originado una mutación de los modelos de gobierno corporativo teniendo como referente esencial las expectativas de los reguladores, los jueces y los mercados. El hecho de que la compañía se reorganice con miras a atender esas expectativas tiene efectos positivos ante los consumidores, las autoridades de regulación y los responsables políticos.

La forma en la que estos actores perciben la empresa cambia cuando saben que la entidad no representa un peligro para la sociedad, pues ha integrado en su modelo de gestión la mitigación de los riesgos a los que puede exponer a la comunidad. La confianza aparece, entonces, como el producto natural de estos modelos de la nueva gobernanza. Las empresas que se vinculan de manera voluntaria a los esfuerzos estatales por alcanzar ciertos fines gozan de beneficios especiales.

Por ejemplo, en caso de que se presenten conductas reprehensibles por parte de sus directivos o colaboradores pueden evitar ser sancionadas. Esto bajo el entendido de que dichos actos se generaron en contra de una política empresarial que desaprueba de forma explícita tales hechos (Manacorda, 2015). En el mismo sentido, la colaboración de la empresa se revela como un factor clave que permite a las autoridades regular el sector económico; pues reduce las asimetrías de información, defecto que obstaculiza una intervención eficaz del Estado.

El modelo de la nueva gobernanza expresaría en el campo del compliance una tendencia similar a la observada por Manne (1962) en materia de responsabilidad social empresarial. Esto es, una reorganización voluntaria de los modelos de gobierno corporativo basada en la aceptación de los criterios que postula la nueva disciplina. Así, la empresa toma conciencia de la importancia que representa cumplir el derecho y de los riesgos que se derivan del incumplimiento, e internaliza esas preocupaciones en su modelo de gestión.
Ahora bien, no se trata de un regreso a los modelos estructurados en torno a la buena voluntad corporativa. Pues la coerción aparece como un ingrediente constitutivo de la buena gobernanza en la medida en que se plantea como el factor a superar. Así, se critica tanto que el Estado pretenda apoyarse en ella para promocionar los valores de los que es portador como la tendencia empresarial a reaccionar solo ante el estímulo punitivo. En ese sentido, análisis como los de Leclair, Ferrer y Ferrer (1997) han hecho referencia a un modelo basado en el enfoque tradicional de la zanahoria y el garrote.

Se trata de generar una cultura corporativa impregnada de preocupaciones éticas como un elemento positivo para los actores económicos, las autoridades y la comunidad. En su defecto, el ejercicio de la potestad sancionatoria se revela como un fracaso de la aspiración de contar con empresas que sean actores positivos del mundo. De la misma forma, la percepción de fracaso se extiende a la manera en la que se ha organizado la empresa, lo cual le ha impedido proteger los bienes jurídicos que tiene bajo su cuidado.

Sin embargo, la reorganización de los modelos de gobierno corporativo dentro de la nueva gobernanza no se limita a la relación que las empresas tienen con las autoridades de regulación. Se extiende a otros asuntos públicos en los que las empresas emergen como actores cruciales. Por ejemplo, en materia del ejercicio del derecho fundamental a la libre expresión, Facebook aparece como el nuevo espacio en el que se ejerce esa libertad de las personas. En el estudio de Kate Klonick (2020) se hace seguimiento a la forma voluntaria en la que esa empresa se ha organizado con miras garantizar de manera independiente e imparcial el ejercicio de ese derecho, con respecto a usuarios provenientes de múltiples países.

En ese caso vemos con claridad una empresa que ejerce funciones propias de un ente público al erigirse como regulador de prácticas sociales relacionadas con el ejercicio de derechos humanos. 
El modelo organizativo que Facebook ha adaptado para esos efectos evoca la forma en la que los Estados se han organizado para cumplir funciones similares. Es decir, adoptando instancias dotadas de independencia jerárquica frente a la gerencia y de autonomía financiera ante la empresa.

\section{Conclusiones}

$\mathrm{E}^{1}$ compliance es una nueva tendencia regulatoria internacional que está transformando la forma en la que se conciben las grandes empresas y su gobierno. La noción se estructura a partir del problema del cumplimiento de la ley y encuentra intolerable la posibilidad de que las compañías vulneren bienes que el derecho considera importantes. Lo anterior, por cuanto las sociedades comerciales son instituciones producto del derecho. En este sentido, solo pueden ser creadas usando herramientas jurídicas, de manera que sus actuaciones no deben tornarse en contra de los valores que el derecho defiende.

Esa afirmación parecería anodina, no obstante, el desarrollo económico ha permitido el advenimiento de organizaciones privadas tentadas a esto, ya que disponen de poderes similares o mayores a los de los Estados. Esa capacidad se ejerce, en buena medida, a escala internacional, ámbito en el que la potestad soberana de los Estados es más débil. De allí que las desviaciones empresariales tienen impactos significativos que es necesario controlar. Ese es un fenómeno que desborda la esfera económica y afecta aspectos fundadores de la vida en comunidad, como, por ejemplo, el respeto de los derechos fundamentales.

Vincular jurídicamente las grandes empresas con la defensa del interés general es en mi concepto el aporte más importante de esta nueva institución. De allí que la organización de la firma y su forma de gobierno dejan de considerarse asuntos de derecho privado que interesan solo a los particulares que en ella invierten. La organización del gobierno corporativo debe garantizar que la actividad económica no tenga impactos negativos sobre toda la comunidad. Esa es una condición que enmarca la generación de dividendos para los accionistas.
Por tanto, las actuaciones empresariales contrarias al derecho son objeto de severas sanciones que afectan tanto a la persona jurídica como a sus dirigentes. La idea es convertir a la empresa en un vector que contribuye a lograr los fines de los que es portador el derecho. Aquellas que se nieguen a insertar su actuación dentro de ese marco pierden el respaldo jurídico. Pues, a la noción de compliance le repugna la posibilidad de empresas que, por designio o desorganización, pretendan sustraerse del cumplimiento de la ley.

La institución que analizamos presta una atención particular a la manera en la que la empresa se gobierna. Lo anterior, a fin de asegurarse de que las compañías asuman el rol de garante de derechos que les corresponde. Por lo tanto, el gobierno de esas organizaciones es un tema de interés para el derecho, pues su desgobierno puede tener graves consecuencias sobre asuntos que desbordan la esfera particular.

Las instituciones propias del compliance tienden a internalizar en la organización empresarial las preocupaciones propias de las autoridades de regulación. De esa forma se genera un nuevo modelo de gobierno corporativo, caracterizado por el condicionamiento jurídico del poder económico, dentro y fuera de la empresa; una aspiración pertinente en el caso colombiano. Pues, en efecto, en el país hemos presenciado empresas emblemáticas involucradas en grandes escándalos; y la experiencia internacional enseña que el sometimiento de las grandes compañías al derecho es una condición necesaria para considerarlas organizaciones positivas para la sociedad. 


\section{Referencias}

Anand, V.; Ashforth, B. E.; Joshi, M. (2004). Business as usual: the acceptance and perpetuation of corruption in organizations. Academy of Management Perspectives, 18(2), 39-53. DOI: https://doi.org/10.5465/ame.2004.13837437

Arias, J. (2020). Epistemología del compliance como criterio de funcionamiento social y empresarial. Pensamiento Jurídico, (52), 181-200. Recuperado de https://bit.ly/3ys9hWu

Arroyo, L.; Nieto, A. (Eds.). (2013). El derecho penal económico en la era compliance. Valencia: Tirant lo Blanch.

Baer, M. H. (2009). Governing corporate compliance. Boston College Law Review, 50(4), 949-1019. Recuperado de https:// bit.ly/3AelnD5

Becker, G. (1968). Crime and punishment: an economic approach. Journal of Political Economy, 76(2), 169-217. DOI : https://doi.org/10.1086/259394

Berle, A.; Means, G. (1932). The modern corporation and private property. New Brunswick: Transaction Publishers.

Borga, N.; Marin, J.; Roda, J. (2018). Compliance: l'entreprise, le régulateur et le juge. París: Dalloz.

Boursier, M. E. (2017). La mondialisation du droit pénal économique, Le droit pénal au défi de la compliance. Revue de science criminelle et de droit penal comparé, (3), 465-480. DOI: https://doi.org/10.3917/rsc.1703.0465

Branston, J. R.; Cowling, K.; Sugden, R. (2006). Corporate governance and the public interest. International Review of Applied Economics, 20(2), 189-212. DOI: https://doi. org/10.1080/02692170600581110

Business Roundtable. (2019). Business Roundtable, statement on the purpose of a corporation. Recuperado de https://bit. ly/3Aeb2qK

Cordier-Palasse, B. (2016) La Compliance Officer: chef d'orchestre du culture change management. En Gaudemet, A. (Dir.) La compliance: un nouveau monde? Aspects d'une mutation du droit (129-138). París: Panthéon-Assas.

Cortina, A. (2003). Las tres edades de la ética empresarial. En Ética de la empresa en la sociedad de la información y las communications. (39-54). Madrid: Trotta.

Danet, D. (2008). Misère de la corporate governance. Revue internationale de droit économique, 22(4), 407-433. DOI: https://doi.org/10.3917/ride.224.0407

Dieux, X. (2013). Shareholdership vs. stakeholdership: what else. En Dieux, Droit, morale et marché. (77-98). Cork: Bruylant.

Dópico, J. (2013). Posición de garante del compliance officer por infracción del deber de control: una aproximación tópica. En L. Arroyo; A.Nieto (Ed.) El derecho penal económico en la era compliance. (337-361). Valencia: Tirant lo Blanch.
Druker, P. (1946). Concept of the corporation. Nueva York: John Day.

Farjat, G. (2004). Pour un droit économique, París: PUF.

Ford, C. (2005). Toward a new model for securities law enforcement. Administrative Law Review, 57(3), 757-828. DOI : https://doi.org/10.2139/ssrn.688004

Friedman, L. (2000). In defense of corporate criminal liability. Harvard Journal of Law \& Public Policy, 23(3), 833-863.

Friedman, M. (1970). The social responsibility of business is to increase its profits. New York Times Magazine, (13), 32-33.

Friedmann, W. G. (1957). Corporate power, government by private groups, and the law. Columbia Law Review, 57(2), 155186. DOI: https://doi.org/10.2307/1119793

Frison-Roche, M.-A. (1995). Le modèle du marché. Archives de Philosophie du Droit, (40), 286-313. Recuperado de https:// bit.ly/3io7Frl

Frison-Roche, M.-A. (2016). Le droit de la régulation. Recueil Dalloz, Chroniques, (7), 610-616.

Frison-Roche, M.-A. (2018). Compliance: avant, maintenant, après. En N. Borga; J.-Cl. Marin; J.-Cl. Roda (Dir.) Compliance: l'entreprise, le régulateur et le juge. (23-36). París: Dalloz.

Frison-Roche, M.-A. (2019) Compliance et personnalité. Recueil Dalloz, (11/7812), 604-606.

Gaillard, E. (1985). Le pouvoir en droit privé. París: Economica.

Garat, M. P. (2018). Compliance de las empresas: un instrumento para el cumplimiento normativo y una garantía para los derechos fundamentales. Revista de la Facultad de Derecho de México, 68(271),555-576. DOI: https://doi.org/10.22201/ fder.24488933e.2018.271.65375

Gaudemet, A. (Dir.). (2016). La compliance: un monde nouveau? Aspects d'une mutation du droit. París: Panthéon-Assas.

Gill, A. (2008). Corporate governance as social responsibility: a research agenda. Berkeley Journal of International Law, 26(2), 452-478. DOI: https://doi.org/10.15779/Z38MS9P

Godechot-Patris, S. (2015). Le law shopping en droit civil et comercial. En S. Dormont y T. Perroud (Dirs.) Droit et marché. (183-193). París: LGDJ.

Gómez-Navarro, C.; Fernández-Riquelme, S. (2019). La acción social empresarial como instrumento de justicia social: la empresa como garante de los derechos humanos. Revista Empresa y Humanismo, 22(1), 43-70. DOI: https://doi. org/10.15581/015.XXII.1.43-70

Gonzalo, J.; San-José, F.; Ruiz-Roqueñi, M. (2017). El moral compliance, una herramienta para facilitar la ética y la sostenibilidad en las organizaciones. Revista de Responsabilidad Social de la Empresa, (26), 15-40. 
Griffith, S. (2015). Corporate governance in an era of compliance. William \& Mary Law Review, 57(6), 2075-2140. Recuperado de https://bit.ly/2VyiZrL

Hasnas, J. (2009). The centenary of a mistake: one hundred years of corporate criminal liability. American Criminal Law Review, 46, 1329-1359. Recuperado de https://bit.ly/3yparC9

Jackman, D. (2015). The compliance revolution. Singapur: Wiley. DOI : https://doi.org/10.1002/9781119045922

Karkkainen, B. C. (2004). New governance in legal thought and in the world: some splitting as antidote to overzealous lumping. Minnesota Law Review, 89, 471-491. Recuperado de https:// bit.ly/3jmYjLV

Klonick, K. (2020). The Facebook oversight board: creating an independent institution to adjudicate online free expression. Yale Law Journal, 129, 2418-2499. Recuperado de https://bit. ly/3xp4B2u

Leclair, D.; Ferrer, O. C.; Ferrer, L. (1997). Federal sentencing guidelines for organizations: legal, ethical, and public policy issues for international marketing. Journal of Public Policy \& Marketing, 16(1), 26-37. DOI: https://doi. org/10.1177\%2F074391569701600104

León, A. (2020). Los programas de cumplimiento penal como objeto de prueba. Revista General de Derecho Procesal, (51), 15-53.

Lobel, O. (2004). The renew deal: the fall of regulation and the rise of governance in contemporary legal thought. Minnesota Law Review, 89, 342-470. Recuperado de https://bit.ly/3lB5HWz

Manacorda, S. (2015). La dynamique des programmes de conformité des entreprises: déclin ou transfiguration du droit pénal des affaires? En A. Supiot (Dir.) L'entreprise dans un monde sans frontières. (191-206). París: Dalloz.

Manne, H. G. (1962). The «higher criticism» of the modern corporation. Columbia Law Review, 62(3), 399-432. DOI: https://doi.org/10.2307/1120051

Mavoungou, L. (2019). Les pouvoirs privés économiques à l'épreuve de la loi française sur le devoir de vigilance. Revue internationale de droit economique, 33(1), 49-62. DOI: https:// doi.org/10.3917/ride.331.0049

Meini-Méndez, I. F. (1998). Responsabilidad penal de los órganos de dirección de la empresa por comportamientos omisivos. El deber de garante del empresario frente a los hechos cometidos por sus subordinados. Revista Derecho PUCP, (52), 883-914. DOI: https://doi.org/10.18800/derechopucp.199901.039

Millon, D. (1990). Theories of the corporation. Duke Law Journal, 39(2), 201-262. DOI: https://doi.org/10.2307/1372611

Missas-Gómez,J. (2018).La responsabilidad penal de las personas jurídicas en Colombia. Problemáticas sobre su aplicación desde la expedición del Código Penal. Criterio Jurídico, 16(1), 69-106. Recuperado de https://bit.ly/37lhDU6
Nodoushani, O.; Nodoushani, P. A. (1999). The debate on corporate governance: an historical analysis of berle and means contributions. Journal of Behavioral and Applied Management, 1(1), 55-66. Recuperado de https://bit.ly/3rQZIhy

Nwanji, T. I.; Howell, K. E. (2007). A review of the two main competing models of corporate governance: the shareholdership model versus the stakeholdership model. Corporate Ownership and Control, 5(1), 9-23. DOI: https:// doi.org/10.22495/cocv5i1p1

Organización para la Cooperación y el Desarrollo Económicos. (2004). Principes de gouvernement d'entreprise. París : OECD Publishing. Recuperado de https://bit.ly/3in8Irq

Organización para la Cooperación y el Desarrollo Económicos. (2011). Promoting compliance with competition law. París: OCDE Publising. Recuperado de https://bit.ly/3Cg94YO

Pereira, B. (2018). L'entreprise et les droits de l'homme: de la confusion et concurrence des règles à l'intelligence normative. Revue interdisciplinaire management, homme entreprise, 7(32), 71-84. DOI: https://doi.org/10.3917/rimhe.032.0071

Ramírez, P.; Ferré O. (2019). Compliance, derecho penal corporativo y buena gobernanza empresarial. Valencia: Tirant lo Blanch.

Reich, C. (2020). The rise of lawless power: a book proposal. The Yale Law Journal, 129, 701-706.

Requena C.; Cardenas S. (2016). Compliance legal de la empresa: una tendencia regulatoria mundial. Ciudad de México: Thomson Reuters.

Reyna, L. (2018). Is this the end of the world as we know it? Gaceta Penal \& Proceso Penal, (104), 223-239.

Ripert, G. (1946). Aspects juridiques du capitalisme moderne. París: LGDJ.

Robé, J. P. (2014). Comment s'assurer que les entreprises respectent l'intérêt général. L'Economie Politique, 4(64), 22-35. DOI: https://doi.org/10.3917/leco.064.0022

Sanclemente-Arciniegas, J. (2018). Evolución conceptual del derecho económico a través de la obra de Gérard Farjat. Revista Pensamiento Jurídico, (48), 31-58. DOI: https://doi. org/10.25100/cdea.v35i65.7748

Sanclemente-Arciniegas, J. (2019). Compliance: norms as an instrument and a threat to the administration. Cuadernos de Administración, 35(65), 118-130.

Sanclemente-Arciniegas, J. (2020). Compliance, empresas y corrupción: una mirada internacional. Derecho PUCP, (85), 9-40. DOI: https://doi.org/10.18800/ derechopucp.202002.001

Santos, B. (1987) Law: a map of misreading. Toward a postmodern conception of law. Journal of Law and Society, 14(3), 279-302. DOI : https://doi.org/10.2307/1410186

Sève, R. (1997). Presentation, en Le privé et le public. Archives de philosophie du droit, 41, 9-12. 
Teubner, G. (2011). Self-constitutionalizing TNCs? On the linkage of «private» and «public» corporate codes of conduct. Indiana Journal of Global Legal Studies, 18(2), 617638. DOI: https://doi.org/10.2979/indjglolegstu.18.2.617

Tricot, J. (2012). Le droit pénal à l'épreuve de la responsabilité des personnes morales: l'exemple français. Revue de Science Criminelle et de Droit Penal Comparé, (1), 19-46. DOI: https:// doi.org/10.3917/rsc.1201.0019

Tricot, J. (2016). La conformité, outil de juridicisation de la RSE et de transformation du Droit. En K. Martin-Chenut; R. Quenaudon (Dirs.) La RSE saisie par le droit perspectives interne et internationale. (303-319). París: Pedone.

Tsuk, D. (2005). From pluralism to individualism: Berle and Means and 20th-century american legal thought. Law \& Social Inquiry, 30(1), 179-225. DOI: https://doi. org/10.1111/j.1747-4469.2005.tb00349.x

Uribe-Manríquez, A. R.; Coca-Vila, I.; Atahuaman-Paucar, J.; Reyna-Alfaro (2017). Compliance y responsabilidad penal de las personas jurídicas, perspectivas comparadas: EEUU, España, Italia, México, Argentina, Colombia, Perú y Ecuador. Ciudad de México: Flores.

Wells, H. (2009). The birth of corporate governance. Seattle University Law Review, 33(4), 1247-1292. Recuperado de https://bit.ly/3Cgcgnp

Whitehouse, L. (2003). Corporate social responsibility, corporate citizenship and the global compact: a new approach to regulating corporate social power? Global Social Policy, 3(3), 299318. DOI: https://doi.org/10.1177/14680181030033002

Woot, P. (1968). Pour une doctrine de l'entreprise. París: Seuil.

Woot, P. (2013). Repenser l'entreprise. Bruselas: Académie Royale de Belgique. 